\title{
Caín y Belerofonte Los límites de dos modelos de racionalidad
}

Jesús Salazar Velasco

Facultad de Filosofía

Universidad Panamericana

jsalazar@mx.up.mx

\section{Los dos grandes libros de Occidente}

Muchos han suscrito la idea que defiende que la Ilíada y la Biblia son los dos grandes libros de Occidente. Pero eso no basta, no nos dice mucho, hace falta comprender las razones por las cuales se puede suscribir esa afirmación; esas razones no se enumeran en un resumen de los efectos, las influencias decisivas, la inspiración que han transmitido durante milenios. Antes bien se les descubre preguntando qué animó su escritura: en el momento en que el autor (los autores) se pregunta por la manera en que puede transmitirle a un pueblo (su pueblo) una historia y un modelo racional. Por lo tanto, no debemos buscar desde el libro hacia aquello que ha generado, no está ahí su riqueza, sino que, más bien, debemos de tratar de estar junto al autor, y nuestra tarea consistirá en comprender los motivos del poeta.

\section{El relato de Caín}

Es bien conocida la historia de Caín, sin embargo, aquí la contaremos haciendo énfasis en algunos pasajes de especial interés para nosotros: el fratricidio y la expulsión de Edén:

Yahvé miró propicio a Abel y su oblación, mas no miró propicios a Caín y su oblación, por lo cual se irritó Caín en gran manera y se abatió su rostro. Yahvé dijo a Caín: «¿Por qué andas irritado, y por qué se ha abatido tu rostro? ¿No es cierto que si obras bien podrás alzarlo? 
Mas, si no obras bien, a la puerta está el pecado acechando como fiera que te codicia, y a quien tienes que dominar». Caín dijo a su hermano Abel: «Vamos afuera». Y cuando estaban en el campo, se lanzó Caín contra su hermano Abel y lo mató. Yahvé dijo a Caín: «¿Dónde está tu hermano Abel?» Contestó: «¿Soy yo acaso el guardián de mi hermano?» Replicó Yahvé: «¿Qué has hecho? Se oye la sangre de tu hermano clamar a mí desde el suelo. Pues bien: maldito seas, lejos de este suelo que abrió su boca para recibir de tu mano la sangre de tu hermano. Aunque labres el suelo, no te dará más su fruto. Vagabundo y errante serás en la tierra». Entonces dijo Caín a Yahvé: «Mi culpa es demasiado grande para soportarla. Es decir que me echas de este suelo y he de esconderme de tu presencia, convertido en vagabundo errante por la tierra, y cualquiera que me encuentre me matará». Yahvé le respondió: «Al contrario, quienquiera que matare a Caín, lo pagará siete veces». Y Yahvé puso una señal a Caín para que nadie que lo encontrase lo atacara. Caín dejó la presencia de Yahvé y se estableció en el país de Nod, al oriente de Edén.

Es el famoso relato de Génesis 4,1-16. ¿Qué nos interesa en particular? El primer punto de atracción para iniciar esta investigación es la afirmación final. Caín, luego del sufrimiento, encuentra la paz: se estableció en el país de Nod, al oriente de Edén, ha dejado de ser un vagabundo y errante. Sin embargo, al final del relato comienza esta investigación, donde recomienza la zozobra, pues dice la edición anotada de la Biblia de Jerusalén, en la nota a pie de página, pequeña y apenas señalada mediante un asterisco difícil de ver: «Nod: país desconocido, cuyo nombre recuerda el epíteto dado a Caín, "errante", nâd, en el país de Nôd».

Si seguimos esa etimología seguiremos la sutil agudeza del autor: Caín habría llegado, por fin, al país del errante, lo que es lo mismo que decir que Caín habría llegado a ningún lugar, pues para el vagabundo y errante no hay país, no hay lugar, cualquier lugar es un lugar más, o mejor, un no lugar. Caín, por lo tanto, no habría dejado de ser, jamás, un vagabundo, y se habría cumplido la sentencia de Dios, y habríamos de olvidarnos de un final feliz para Caín. La sagacidad del autor, el trato que da a Caín, es sorprendente, estremecedor, y sin embargo, veremos que no es una simple ironía, sino que revela el motivo de la paradoja. 


\section{El relato de Belerofonte}

En el canto VI de la Ilíada se encuentra lo que algunos estudiosos han llamado un «encuentro extraño»: Diomedes y Glauco, de bandos contrarios, dejan la guerra, escuchan los relatos de sus antecesores, y al final intercambian las armas y se marchan a buscar otros enemigos. En el marco de tan extraordinario encuentro, ensalzado por la hermosa conversación entre Héctor y Andrómaca, se halla el relato de Belerofonte, que citamos en aquello que nos interesa por ser menos conocido que el de Caín:

...y Glauco el padre era de aquel Belerofonte el intachable. A este dieron los dioses belleza y, además, virilidad amable; más en su corazón desgracias contra él maquinó Preto, el cual, precisamente, del territorio argivo lo expulsó (...) Y es que por este hombre volvióse loca la mujer de Preto, Antea la divina, ansiosa por ajuntarse con él en amores a ocultas, pero no conseguía en nada persuadir al buen Belerofonte, tan bien intencionado. Y ella, entonces, mintiendo, al rey Preto decía: "iAsí te quedes muerto, Preto, mata tú a Belerofonte, que en amores conmigo quería unirse sin que yo lo quisiera!». Así dijo, y la cólera adueñóse del rey en cuanto oyó tales palabras. Matarle rehuía, pues tal acción en su ánimo temió, mas a Licia lo enviaba y signos luctuosos procuróle que en tablilla plegable él escribiera, abundantes señales que el ánimo consumen, y a su suegro ordenábale mostrarlas para que pereciera. Pero aquél marchó a Licia al amparo de escolta irreprochable: la de los dioses (...) Mas cuando ya la décima aurora con sus dedos de rosa apareció, entonces justamente le interrogaba [Yóbates, suegro de Preto, a Belerofonte] y los signos escritos le pedía (...) mandóle entonces que primeramente matara a la Quimera, la espantosa (...) y la mató, no obstante, porque aquél hizo caso de los presagios que envían los dioses. En segundo lugar, luchó contra los sólimos gloriosos (...) Como tercera prueba, mató a las varoniles amazonas; mas cuando, justamente, regresaba le tramaba otra astuta añagaza: seleccionó varones distinguidos por toda la ancha Licia y los puso al acecho en emboscada; pero ellos nunca jamás de nuevo a sus casas habrían de volver (...) No obstante, cuando ya el rey iba comprendiendo que aquél retoño noble era, por cierto, de alguno de los dioses, allí mismo intentaba retenerle y a su propia hija le ofrecía por esposa y la mitad le dio de toda su real honra (...) Y la reina parió para Belerofonte, el héroe sen- 
sato, estos tres hijos (...) Mas cuando ya también Belerofonte odioso se hizo a todos los dioses, entonces, en verdad, andaba errante y solo por la llanura Alea, concomiéndose el alma y evitando la huella de los hombres.

Este es el segundo gran motivo de nuestra investigación: Ilíada 6.155-203. Ya se ve que hay semejanzas con el relato de Caín, pero comenzaremos por la más sorprendente de ellas: dice la edición anotada de la Ilíada, al referirse a la llanura Alea: «posiblemente, nombre inventado por el poeta, que creó una denominación de la misma raíz que la de la forma verbal alâto, "andaba errante", como adjetivo de alê, "vagabundeo", "extravío"»"

Belerofonte habría sido - por volverse odioso a los diosesun vagabundo finalmente: el final feliz hallado en el matrimonio con la hija del rey Yóbates terminó en infeliz errancia en la llanura Alea, que es también el lugar del vagabundo, ningún lugar, cualquier lugar.

Si bien sorprenden otros grandes motivos - las tablillas con inscripciones de muerte, el cese al combate entre Diómedes y Glauco, la muerte de Quimera y su simbolismo en la antigüedad, consideramos que el destino final de los protagonistas de estas historias es el punto más alto del paralelismo, y al mismo tiempo, es de donde se obtendrá el sentido general de los relatos.

Se aclara entonces el interés: ¿cómo es posible que hayan concluido, Homero y el autor del Génesis, de idéntica manera sus relatos?

\section{Dos relatos paralelos}

Mencionamos el paralelismo de los relatos, algunos de estos elementos se explican más adelante:

- Origen triangular del conflicto (Caín, Abel, Yahvé / Belerofonte; Antea, Preto).

- Resolución violenta del conflicto: maldición, expulsión, destierro.

${ }^{1}$ Homero, Ilíada, trad. Antonio López Eire, Madrid: Cátedra 1999. 
- Negación de la muerte que se debía en justicia.

- Portan señales acerca de su muerte.

- No pueden ser muertos por enemigos.

- Son odiosos a los ojos de la divinidad - aunque Belerofonte en principio es protegido por los dioses, termina enemistándose con ellos-.

- Se alojan finalmente en un país: Nod, Alea.

- Dinámica de perseguido - perseguidor - apestado.

A primera vista, la pregunta es sobre la posibilidad de un origen común de los relatos. Este paralelismo y esta pregunta ha sido ya formulada, al menos en tiempos cercanos, por White, en «Bellerophon in the 'Land of $\operatorname{Nod}^{\prime} »^{2}$. White señala que las relaciones entre los mitos semíticos y los griegos no nos sorprenden más, pero aquí estamos en contra de esa postura. Como es bien sabido, la lectura común es asociar los mitos griegos con algún relato de $\mathrm{Me-}$ dio Oriente o el norte de África - en especial de Egipto-, y como bien señala White, considerando, más que la transmisión directa de textos, una influencia a través del intercambio cultural donde el mediador habrían sido las personas de los pueblos y no directamente sus instituciones. En particular, en el caso de los mitos que nos conciernen, a través del pueblo Licio, como se verá más adelante.

La importancia del estudio de White es que pone sobre la mesa los ingredientes de nuestra investigación, pero al mismo tiempo nos pone sobre la pista de preguntas más interesantes. White se remite, en primer lugar, a dilucidar la etimología del nombre del héroe griego: Belerofonte podría ser un nombre compuesto por muy diversos motivos ${ }^{3}$, sin embargo, es comúnmente reconocida la etimología del nombre parlante: Belerofonte, que se llamaba Hipónoo, quiere decir «matador de Bélero», «asesino de Bélero», por

2 Jeffrey A. White, «Bellerophon in the 'Land of Nod': Some Notes on Iliad 6.153-211», The American Journal of Philology 103-2 (1982), pp. 119-127.

${ }^{3}$ Cf. White, «Bellerophon in the...», pp. 120-121. Una explicación del nombre de Belerofonte lo asocia a la deidad fenicia-cananita Baal; otra explicación lo hace significar «héroe que aparece en las nubes». 
haber dado muerte a Bélero, príncipe de Corinto. Así lo confirma Graves en su celebre estudio Los mitos griegos: «Belerofonte, hijo de Glauco y nieto de Sísifo, tuvo que abandonar Corinto después de haber matado a un tal Bélero - lo que le ganó el nombre de Belerofonte, cuya abreviación es Belerofón - y luego a su propio hermano, al que normalmente se le da el nombre de Delíades» ${ }^{4}$.

Belerofonte, por lo tanto, es un asesino, y además fratricida. La salida de Corinto se explica por sí misma: huía de su crimen, o bien, visto de otro modo, cumplía la pena asignada al homicidio: la expulsión de la ciudad. Homero no nos dice que Belerofonte haya sido un homicida, ni del príncipe ni de su hermano, y ello es de capital importancia para comprender el final de la historia, y para comprender que el relato en la Ilíada, en cierto sentido, sea incomprensible tal como está narrado ahí simpliciter. Por el mismo motivo, no es evidente que, además de cumplir su pena, Belerofonte haya huido por otra razón: buscar purificación de sus crímenes. Que esta razón sea de peso se constata por dos motivos: por la significación del homicidio y la mancha de sangre, y por la legislación sobre el crimen. Por otro lado, el tema de la purificación es un tópico común en los relatos antiguos. El paralelismo en el fratricidio es, como escribe White, el motivo de semejanza entre Caín y Belerofonte, pero no es un motivo suficientemente grande para que sea el determinante en una investigación: el homicidio es común en los relatos antiguos.

Al inicio de los relatos, además, aparece otra semejanza: si bien hemos mencionado que se trata en ambos casos de un triángulo violento, en el caso de Belerofonte el triángulo amoroso con la reina Antea y el rey Preto recuerda la historia bíblica de José, como uno de los varios triángulos de deseo violentos ${ }^{5}$. Graves da cuenta de la semejanza entre Belerofonte y José, pero en ningún momento da cuenta de la relación entre Belerofonte y Caín. Pensamos que, como bien señala White, esta relación adquiere relevancia por el final de los relatos, más que por sus inicios y desarrollos, aunque

${ }^{4}$ Robert Graves, Los mitos griegos, Madrid: Alianza 2004, p. 336.

${ }^{5}$ White ofrece un ilustrativo recuento de estos triángulos, y los relaciona con un antiguo mito egipcio, cf. White, «Bellerophon in the...», p. 123. 
quizá haya un motivo que aún antes del desenlace atiza la curiosidad: la señal que portan los homicidas.

White se da cuenta de algo más, pero no alcanza a percatarse de la importancia de su intuición. En una nota a pie de página señala que, «extrañamente», Homero no menciona en ningún momento que Belerofonte recurrió al Pegaso para lograr salir avante en sus luchas ${ }^{6}$. Graves sí lo menciona en el recuento del mito de Belerofonte, cuando habla del modo en que el héroe venció a Quimera: «Antes de comenzar tal empresa, Belerofonte consultó al divino Poliido, quien le aconsejó que atrapara y domara al caballo alado Pegaso, amado por las Musas del Helicón, para las que había creado el pozo Hipocrena, pisoteando la tierra con sus cascos en forma de luna» ${ }^{7}$. Homero simplemente dice al respecto: «y la mató, no obstante, porque aquél hizo caso de los presagios que envían los dioses», sin explicitar el modus operandi de Belerofonte al recurrir a Pegaso.

Sin embargo, Homero supone el mito, pues supone su desenlace: el enojo de los dioses. Según el mito griego, apuntado por Graves: «En el momento culminante de su gloria [la muerte a Quimera, los sólimos, las amazonas, la emboscada, la honra que le dio el rey Yóbates], Belerofonte emprendió presuntuosamente un vuelo al Olimpo, como si fuera inmortal, pero Zeus envió un tábano que picó a Pegaso bajo la cola, haciendo que se encabritara y arrojara a Belerofonte vergonzosamente a la tierra. Pegaso completó su vuelo al Olimpo, donde Zeus lo utiliza ahora como bestia de carga para sus rayos; y Belerofonte, que había caído en un seto de espinos, quedó vagando por la tierra cojo, ciego, solo y maldito, evitando siempre los caminos de los hombres, hasta que la muerte se lo llevó» ${ }^{8}$. A esta osadía algunos la han llamado «vanidad». Desde nuestra interpretación, esta explicación sobre por qué Belerofonte fue odiado por los dioses debe ser sometida a revisión, pues es posible que haya otra causa que explique el fenómeno. White califica el intento de Belerofonte de llegar al Olimpo como un exceso de

6 White, «Bellerophon in the...», p. 124.

7 Graves, Los mitos griegos, p. 336.

${ }^{8}$ Graves, Los mitos griegos, p. 338. 
heroísmo, some act of heroic excess, siguiendo a Píndaro (Isthm. 7.4348). Sin embargo, como veremos más adelante, no se trata sólo de vanidad o exceso de heroísmo, hay un motivo más poderoso.

Llama la atención la forma en que White enfatiza la presencia del mal en el mito de Belerofonte: para White el mal está presente, en primer lugar, en Quimera, y en segundo lugar en el pueblo sólimo ${ }^{9}$. Sobre Quimera también se ha escrito mucho, y nuestro interés se centra en señalar que el mal no viene, en primera instancia, representado por Quimera, sino por el propio Belerofonte fratricida.

Luego de Quimera, la siguiente prueba fue la lucha con el pueblo sólimo. No se trata de cualquier alusión, ¿cuál no es la importancia de este pueblo en ambos relatos que el nombre de Jerusalén deriva de ellos? Tácito ya lo consigna ${ }^{10}$, pues Solymi es el nombre genérico de un grupo de pueblos semitas de Asia Menor que invadió al pueblo licio ${ }^{11}$. «Jerusalén quiere decir ciudad o fundación del dios Šlm, "estrella de la tarde", un dios importante de Siria y Palestina mencionado en los textos ugaríticos» ${ }^{12}$.

Como Caín, Belerofonte es un «héroe cultural»" Caín, según indica la continuación del relato, construyó una ciudad, tuvo descendencia, y de los hijos de sus hijos nacieron «los que habitan en tiendas y crían ganado... cuantos tocan la cítara y la flauta... los forjadores de cobre y hierro» ${ }^{14}$. Belerofonte fue a su vez heredero del rey Yóbates y labró la tierra con buenos frutos. Sin embargo, esta condición no duraría mucho tiempo en ninguno de ellos.

Finalmente, el gran motivo de estudio de White es la llanura Alea. Coincide con aquellos que disciernen en el nombre del lugar un juego de palabras: «el nombre es un juego sobre alāto, de alāomai (...) que quiere decir "la llanura de la errancia", un concepto metafórico de estado caído, condición de exilio, miseria,

9 Whiтe, «Bellerophon in the...», p. 125.

10 Clara alii Iudeaorum initia, Solymos, carminibus Homeri celebratam gentem, conditae urbi Hierosolyma nomen e suo fecisse, en Historiae 5. 2, cit. en: WhiтE, «Bellerophon in the...», p. 125.

11 Whiте, «Bellerophon in the...», p. 125.

12 Wніте, «Bellerophon in the...», p. 125.

13 White, «Bellerophon in the...», p. 126.

14 Génesis 5, 20-22. 
vulnerabilidad, distracción» ${ }^{15}$. Es muy probable que sea el propio White quien ahora cometa un exceso, pues el estado de caído corresponde a una categoría semítica difícilmente asimilable en la antigüedad griega. Sin embargo, acierta al relacionar de manera definitiva a Caín y Belerofonte por su condición. Ahora bien, nos corresponde a nosotros aclarar el motivo de ese cambio de estado o de condición en ambos relatos, que, consideramos, no es imputable meramente al exceso de vanidad de Belerofonte, ni tan sólo al pecado per se en Caín: la errancia definitiva, sin reposo en ningún lugar, ni en Nod ni en Alea, no proviene sólo de la vanidad de Belerofonte y el pecado de Caín, sino de una explicación distinta. White concluye su estudio sin decirnos más: «La llanura Alea y el país de Nod son el mismo lugar físico» ${ }^{16}$. Pero son algo más que eso, son un locus más que físico, representan la manera en que se retrata la condición de los dos apátridas, son el sello que se imprime a esos personajes, más que un simple paradero paradójico.

\section{La explicación del destierro: la sangre}

White nos ha introducido al tema, pero no nos ha llevado hasta su corazón. Las explicaciones han sido lógicas, pero no reales, plausibles pero no convincentes. En otro estudio encontramos una huella más fresca que nos permite remontarnos al misterio que nos plantean los relatos. En un pequeño artículo, publicado muchos años antes que el estudio de White, Lockwood nos conduce mar adentro, al estudiar un pasaje del Paraíso perdido de Milton: «Ninguno de los comentadores explica claramente por qué Belerofonte tuvo que errar solo, o por qué en esta llanura en particular» ${ }^{17}$. Al igual que White, Newton considera que el destino de Belerofonte

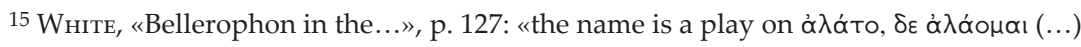
it means the "Plain of Wandering", a metaphorical conceit for a fallen state, for a condition of exile, misery, vulnerability, distraction».

16 Wніте, «Bellerophon in the...», p. 127.

17 Laura E. Lockwood, «Paradise Lost, VII, 15-20», Modern Language Notes 28-4 (1913), pp. 126-127. 
fue marcado por su «sed de gloria» ${ }^{18}$. Con mayor fortuna, Lockwood señala que Homero sabe que Beleronte debe ser castigado con el exilio, tal como lo atestigua el mito, pero que no sabe cuál es la razón del castigo, y quizá por ello hace bien en no señalar de manera explícita el intento de ascenso al Olimpo; aunque, si acepta la forma tradicional del mito, de alguna manera acepta lo que el mito explica - el «exceso de heroísmo» de Belerofonte-.

En este sentido, Lockwood da luces: «Homero conoce la mitad de la historia que refiere Milton [el lamento de Belerofonte]; sabe de la errancia, pero no entiende la razón por la que Belerofonte debe ser condenado a una vida de castigo ${ }^{19} \gg$. De tal manera que Homero conoce la forma tradicional del mito, la supone, no la niega en su narración, pero tampoco la suscribe, y esto, dice Lockwood, porque «no entiende la razón por la que Belerofonte debe ser condenado a una vida de castigo». Por otro lado, Píndaro sí da una razón - como ya anunciaba White-, o acepta una razón, pero no es la razón correcta: «Píndaro atribuye la causa a la caída de Pegaso, pero no menciona para nada la errancia y la soledad ${ }^{20}$ que sí mencionan Homero y Milton. En este sentido, Graves parece seguir fácilmente la explicación de Píndaro.

«La pregunta es, ¿por qué un aspirante a honores divinos es odiado por todos los dioses y es condenado a un destino severo sin esperanza de liberación?» ${ }^{21}$. Lockwood recuerda el estudio de Harrison sobre religión griega y apunta a una respuesta mejor: «La sangre envenena la tierra, y además envenena al asesino alimentado por la tierra» ${ }^{22}$. La sangre es la explicación del destierro de Belerofonte, y no el exceso de heroísmo; la sangre derramada

18 Cit. en: Lockwood, «Paradise Lost...», p. 126: «Attempting vain-gloriously to mount up to Heaven».

19 Lockwood, «Paradise Lost...», p. 126.

${ }^{20}$ Lockwood, «Paradise Lost...», p. 126.

21 «The question is, why should an aspirant to divine honors have been hated of all the gods, and have been condemned to so severe a fate without hope of release?», en: LockwoOD, «Paradise Lost...», p. 126.

22 «The blood poisons the earth, and thereby poisons the murderer fed by the earth», en Jane E. Harrison: Prolegomena to Greek Religion, pp. 219-221. Cit. en: Lockwood, «Paradise Lost...", p. 127. 
por su propia mano al matar al príncipe y a su hermano; la sangre injustamente derramada envenena la tierra y al sujeto.

Harrison da cuenta de la extraña narración de Homero y la explica: «En Homero el fin de Belerofonte es misterioso (...) Homero, con el instinto del poeta por lo romántico y misterioso, no responde a la pregunta; Píndaro, con su prejuicio olímpico, ve en la caída de Belerofonte lo merecido por su "insolencia” (...]) Pero los mitógrafos saben la razón real de la locura y la errancia, saben del antiguo pecado contra el antiguo orden ${ }^{23}$. Ahí se encuentra la explicación del paradójico destino de Belerofonte y extendemos la explicación al destino de Caín: la «culpa de la sangre». Belerofonte fue hacia Proteo en busca de purificación, pero no la consiguió, y no lo consiguió porque no podía ser así en aquellos tiempos. A reserva de continuar la exploración de los motivos de los poetas para desterrar a Caín y a Belerofonte, es preciso indagar también en los usos y costumbres arraigados en la ley al momento de castigar a un homicida.

El paradójico destino de Caín y Belerofonte se explica, en primer lugar, por lo que hay de más importante en sus historias: el fratricidio. Sin embargo, el castigo no sólo es justo - el destierro-, sino que es trágico. Lo que nos sorprende no es que sean castigados por haber dado muerte a sus hermanos, sino que sean expulsados a una tierra inexistente, sin nombre real, y con una clara alusión a «la tierra de nadie», el "país de la errancia», el «país de ningún lugar», o simplemente «el no lugar». Dicho de otro modo, más que el castigo nos inquieta la ironía con que se trata a los personajes. Pero para comprender mejor esta pregunta definitiva es necesario comprender antes el castigo por el homicidio a la propia sangre.

La explicación de la sangre: el antiguo orden

Es asunto viejo atraer el estudio de Homero al estudio de los mitos semitas, y explicar la cuestión homérica a través de la cuestión 
semítica. Muy amplios estudios hay al respecto, sin embargo, la mayoría se circunscribe a la mitografía y la filología ${ }^{24}$. Algunos consideran descubrir el corazón del mito en la tablilla con signos luctuosos que porta Belerofonte, y discutir si lo que está escrito son letras, dibujos o algún mensaje críptico $^{25}$. Y parece que nosotros mismos estamos a punto de sentenciar que el corazón del mito está en comprender a la región Alea como análoga del país de Nod; no pensamos de esa manera, pero consideramos que se trata del momento de mayor perplejidad del relato, y por lo tanto, el que más despierta la curiosidad - cuando de estudiar el paralelismo se trata - y el mejor motivo para aproximarse a los mitos.

Sin embargo, nuestra investigación nos ha llevado, nuevamente, al punto inicial de los relatos: el fratricidio. La sangre derramada juega un papel muy importante en los dos mitos. Aunque a primera vista esto es evidente en Génesis - por el explícito reclamo de Yahvé-, Lockwood nos ha explicado ya la importancia de la sangre en el mito de Belerofonte. Hemos dicho también que, además del derramamiento de sangre, es preciso revisar la pena al crimen.

Que la muerte, y de modo explícito, el derramamiento de sangre sea un tema importante en Génesis y la Ilíada, es un asunto a todas luces evidente. Feldman considera que de hecho se trata de una de las actitudes morales del autor del Génesis ${ }^{26}$. Homero, por su parte, en medio de una guerra, necesariamente considera la sangre, y la describe como la vida misma del guerrero. Cuando Afrodita es herida por Diómedes escribe Homero: «y de la diosa sangre iba fluyendo / inmortal, el icor, cual fluir suele / a los felices dioses, porque no comen pan, / no beben vino de ardientes reflejos; / por eso ellos carecen de sangre / y reciben el nombre de

24 Puhvel, por ejemplo, explica las palabras de Homero según la escritura semítica, y sin embargo, aunque de una erudición extraordinaria, no nos dice nada del sentido del poema de Homero. Cf. Jaan Punvel, «Homeric Questions, and Hitite Answers», The American Journal of Philology 4-3 (1983), pp. 217-227.

${ }^{25}$ Cf. Nathaniel Schmidt, «Bellerophon's Tablet and the Homeric Question in the Light of Oriental Research», Transactions and Proceedings of the American Philological Association 51 (1920), pp. 56-70.

26 Shammai Feldman, «Biblical Motives and Sources», Journal of Eastern Studies 22-2 (1963), pp. 73-103. 
inmortales» (Il. 5.340-343). Señalando que la inmortalidad radica en poseer icor y no sangre; o de otro modo, expresando que la vida mortal está en la sangre.

Por su parte, en el estudio de Génesis, Buttenwieser ofrece un análisis útil al respecto; el autor se propone estudiar «las condiciones en las cuales un asesinato admite la venganza de sangre» ${ }^{27}$ como venganza en caso de muerte injusta. La primera observación que hace es que un asesinato es digno de venganza de sangre cuando el cuerpo de la víctima no es enterrado y permanece «descubierto, sin absorber por la tierra». En este sentido señala el paradigmático pasaje de Job 16. 18: «¡No cubras, tierra, mi sangre! ¡Que nada pare mis gritos!».

El pasaje de Job, contrastable con el asesinato de Abel, muestra varios aspectos importantes. En primer lugar, y tal como lo muestra el mito hebreo que da origen al relato de la muerte de Caín, existe una clara relación entre sangre y cuerpo, que si bien no son sinónimos en todos los casos, puede usarse el uno por el otro en ocasiones. Un ejemplo de ello es Lev. 17, 14: «Porque la vida de toda carne está en su sangre». En Génesis se lee: «¿Qué has hecho? Se oye la sangre de tu hermano clamar a mí desde el suelo». Aquí, a primera vista, es la sangre de Abel la que clama a Yahvé, pero en el mito recogido por Graves se comprende que es la sangre que clama desde la tierra, o bien el cuerpo no enterrado de Abel, o bien las dos cosas:

El espíritu de Abel escapó de su cuerpo, pero no pudo hallar refugio en el Cielo - donde ninguna otra alma había ascendido todavía - ni en el Abismo - donde ninguna otra alma había descendido aún-. Por ello se quedó revoloteando por las cercanías (...) Otros sostienen que la tierra bebió la sangre de Abel pero se negó a aceptar su carne (...) cada vez que [Caín] intentaba enterrar su cadáver, la Tierra lo vomitaba a la superficie, hasta que al fin exclamó: «iNo acogeré ningún cuerpo hasta que la arcilla con la que se formó a Adán me haya sido devuelta! $\gg^{28}$.

27 Moses Buttenwieser, «Blood Revenge and Burial Rites in Ancient Israel», Journal of the American Oriental Society 39 (1919), p. 303.

28 R. Graves y R. Patai, Los mitos hebreos, Madrid: Alianza 2004, pp. 113-115. 
Los cabos están sueltos: a) en primer lugar se trata de una muerte que da lugar a la venganza de sangre, pues es injusta y prematura; b) la sangre clama justicia, independientemente de si se le dio sepultura al cuerpo de Abel (en este sentido, los griegos parecen hacer más caso a la sepultura que a la voz de la sangre, así lo hace notar Homero cuando se trata del diálogo de Héctor antes de morir en manos de Aquiles, y de Príamo al reclamar el cuerpo de su hijo a su ejecutor); c) lo mismo en el caso de Caín que de Belerofonte, el homicidio estigmatiza al asesino; d) además, en ambos casos se sucede una pena por la injusticia cometida.

Este último punto es el que ahora nos interesa para explicar el destierro de ambos personajes al «País de ningún lugar». Como afirma Buttenwieser: «el punto decisivo es que en Israel, como en los demás pueblos antiguos [entre ellos el pueblo griego], existía la noción de que una muerte violenta clama por venganza sólo mientras la sangre permanezca sin cubrir o, lo que es lo mismo, mientras el cuerpo permaneciera sin enterrar ${ }^{29}$. En el caso de Abel, tal parece que su sangre sí penetró la tierra, pero el relato conserva de manera implícita los rasgos que Graves consigna en el mito antiguo, a saber, que su alma no halló descanso, o bien que su cuerpo permaneció al descubierto y no pudo ser enterrado, por lo cual, la venganza de sangre es posible, aunque estos detalles no aparecen en el relato de Génesis de manera explícita.

En el caso de Abel, Graves nos muestra además que en el mito antiguo se conserva la norma de la venganza de sangre: el alma de Abel se convierte en un alma en pena que no halla descanso. Pero el relato de Génesis no se detiene en ello, sino que avanza hasta señalar que el hombre que inició el exilio y el destierro fue Caín, y no el alma de Abel. De la misma manera, el relato homérico no repara en la muerte del hermano de Belerofonte, sino que se continúa al exilio del héroe.

Buttenwieser nos da algunos elementos de importancia: el exi-

${ }^{29}$ Buttenwieser, «Blood Revenge and...», p. 304: «The decisive point is that neither in Israel nor among any other people of ancient times did the notion exist that violent death called for vengeance only as the blood remained uncovered, or, what is the same thing, as long as the slain one was left unburied». 
lio es temporal sólo en caso de homicidio accidental, y en caso de que este exilio no se lleve a cabo o no se cumpla el plazo exigido de destierro, entonces puede venir la venganza de sangre; en caso de que se cumpla en tiempo y forma, no es posible la venganza de sangre y se exige el perdón al homicida; esto es común a Grecia e Israel $^{30}$.

Sin embargo hay diferencias de leyes entre los pueblos: «mientras que los griegos permitían a los allegados a la persona asesinada dar perdón inmediato al homicida y liberarlo del exilio, ya sea que mediara o no un pago de dinero de sangre, los hebreos prohibían esta práctica» ${ }^{31}$. El perdón por medio del pago de dinero de sangre prevalecía en tiempos homéricos, así como en Israel en tiempo previos al exilio, y solamente en el caso del homicidio accidental. Pero en el pueblo de Israel la práctica no continuó, como se ve en $2^{\circ}$ Samuel 21, 4: «No es para nosotros cuestión de oro ni plata con Saúl y su casa, ni se trata de hacer morir a nadie en Israel».

En todo caso, en el homicidio intencional, el perdón no era posible para ninguno de los dos pueblos, y se exigía el destierro del asesino con carácter definitivo: Caín y Belerofonte no podrían regresar nunca a su tierra. La purificación sería por el resto de los días del homicida, buscarán refugio en alguna otra ciudad o pueblo destinado a ello, y así explicamos mejor que hallan sido alojados en el país de Nod y en la región Alea, y sin embargo se mantiene en pie la pregunta ¿por qué la ironía de los autores en destinarlos a una tierra inexistente y que además lleva nombre de «País de ningún lugar»? Al hacerlos llegar a un lugar -Nod, Alea-, se cumple con la norma, la ley se lleva a cabo, pero al jugar con el nombre del lugar, una vez cumplida la ley, se quiere decir algo más. La pregunta es: ¿qué nos quieren decir? La estrategia en ambos casos es impecable, el narrador cumple con su deber ante la ley, pero se escapa de ella para mostrarnos algo más.

La respuesta a esta pregunta podemos buscarla, aún, tratando

30 Buttenwieser, «Blood Revenge and...», p. 307.

31 Buttenwieser, «Blood Revenge and...», p. 308: «while the former [the Greek] allowed the kin of the person to grant his slayer immediate pardon and release from exile, whether with or without payment of blood-money, the latter [the Hebrew] interdicted this practice». 
de comprender el tema de la sangre en el homicidio. La sangre no sólo mancha al asesino, sino que esteriliza la tierra: «El país entero será visitado con calamidad si el derramamiento de sangre no es ajusticiado» ${ }^{32}$. Y esta maldición podría permanecer durante generaciones. Buttenwieser, llegado a este punto, señala una posible explicación: se trata de una ofensa a Gea o Madre Tierra, una diosa antigua. En última instancia, por lo tanto, se trataría no solamente de una injusticia, de un acto criminal contra el orden humano, sino también de un crimen religioso: tanto en los griegos como en los hebreos, tanto en Belerofonte como en Caín, la ofensa radical es un crimen religioso. El enojo de Yahvé en Génesis y de los dioses en Ilíada vendría dictado por la muerte de los hermanos de los personajes, pero ello no explica el destierro paradójico a Nod y Alea; la explicación se encuentra en la ofensa a la Madre Tierra, y su castigo consistiría en negarles sitio sobre la tierra para descansar.

\section{Caín y Belerofonte: los apestados}

Caín y Belerofonte pueden ser leídos también como el mismo personaje, o mejor, podemos descubrir en ambos casos la misma estructura de personaje. La sucesión de acontecimientos nos muestra al héroe que es perseguido y perseguidor, o lo que es lo mismo, siguiendo la teoría del chivo expiatorio de René Girard, acusado y acusador. Girard ofrece una explicación del chivo expiatorio como la relación que se establece entre acusado y acusadores, y da una interpretación religiosa o sacralizada del fenómeno: el chivo es acusado por sus capacidades demoníacas, y posteriormente es sacrificado y revestido de poderes bondadosos propios de un dios, pues su presencia maléfica habría causado los males que padece la sociedad y su sacrificio habría recuperado la salud las relaciones sociales, logro posible sólo para un ser divino bondadoso ${ }^{33}$. El perseguido y el perseguidor se encuentran, en la teoría del chivo

32 Buttenwieser, «Blood Revenge and...», p. 309: «The whole country might be visited with calamity if bloodshed were not duly avenged».

33 Cf. René Girard, El chivo expiatorio, Barcelona: Anagrama 2002. 
expiatorio de Girard, en distintos personajes. Sin embargo, Caín y Belerofonte son al mismo tiempo perseguidos y perseguidores.

Caín es originalmente un perseguido: «¿Por qué andas irritado, y por qué se ha abatido tu rostro? ¿No es cierto que si obras bien podrás alzarlo? Mas, si no obras bien, a la puerta está el pecado acechando como fiera que te codicia, y a quien tienes que dominar». Para el relato bíblico es de vital importancia dejar claro que Caín no se encuentra tranquilo, que hay una riesgosa acusación a la sombra: el pecado. Para la literatura bíblica, claramente en Job, no olvidemos, Satán es el acusador. De tal suerte, Caín es en primer lugar un perseguido por el pecado. La dinámica se invierte inmediatamente, y Caín pronto es un perseguidor o acusador: en este momento el perseguido es Abel, hasta la muerte. Si Caín perseguido es un hombre tentado, Caín perseguidor es un asesino. ¿Cómo se resuelve esta oposición perseguido - perseguidor? Con una nueva figura: Caín el apestado. Como en la enfermedad, Caín padece la acusación del pecado - como el enfermo padece la enfermedad - y lleva la acusación consigo como acusador con la muerte a su hermano - como el enfermo que contagia al que es cercano-. El apestado, figura típica de la violenta relación entre el acusador y el acusado, el perseguido y el perseguidor, reúne los elementos antagónicos, esta vez, en un solo sujeto: Caín es acusador, porta el mal, y por eso permanecerá en adelante a la sombra ante la mirada de Yahvé, a quien le dice: «he de esconderme de tu presencia»; Caín es acusador, no por llevar la injuria a otro, sino por encarnarla, es la dimensión que se activa con el pecado cometido. Caín también es un acusado, y por eso puede ser sujeto de la venganza de sangre, y sus palabras son clarividentes: «cualquiera que me encuentre me matará».

Belerofonte, a su vez, puede ser leído en la misma clave, si bien es cierto que la sucesión cronológica de los acontecimientos es distinta en su caso. Belerofonte es, en primer lugar, un perseguidor, y por ello es un asesino, homicida y fratricida, aunque el relato no lo menciona de manera directa sino solamente por conservar el apodo de «asesino de Bélero» y no su nombre, Hipónoo. Homero, una vez que ha supuesto la condición de acusador de Belerofonte, prefiere mostrar - quizá porque desconoce los motivos, como ya 
se ha dicho - al Belerofonte perseguido o acusado - injustamente, en este caso-, poniendo a Preto como su acusador, impostando una figura que explique su condición - Preto no es en realidad un acusador, sino un justo demandante-. Finalmente, Belerofonte es un apestado: «concomiéndose el alma y evitando la huella de los hombres», Belerofonte representa al acusador - no alcanza a purificarse de sus asesinatos - y es públicamente acusado - a pesar de haber recibido honra de parte de Yóbates, su condición indeleble y su caída de un puesto noble marcan al acusado-.

\section{La racionalidad en los relatos}

En otro estudio hemos indicado algo relativo al destino de Caín, aludiendo a la clarividencia que muestra cuando anticipa lo que podrá ocurrirle en el destierro: «Mi culpa es demasiado grande para soportarla. Es decir que me echas de este suelo y he de esconderme de tu presencia, convertido en vagabundo errante por la tierra, $y$ cualquiera que me encuentre me matará». En aquél lugar ${ }^{34}$ afirmamos que la clarividencia de Caín consistía en anticipar su posible muerte a manos de un tercero por encontrarse vulnerable en el exilio: la condición de destierro hace débil y vulnerable a cualquier sujeto. Sin embargo, hoy podemos matizar aquella afirmación. En efecto, Caín es clarividente, pero el motivo para temer su muerte se encuentra anclado en la propia legislación de la época: el castigo por el fratricidio y la posibilidad de la venganza de sangre. Además, la clarividencia de Caín es, más bien, limitada, pues anticipa que puede ser muerto, pero no puede anticipar que nunca dejará de ser vagabundo. En este sentido, ¿cómo debemos comprender las palabras de Yahvé al protegerlo de la muerte con una señal? ¿Debemos pensar que es un acto de misericordia, o de sumo castigo? Según lo que hemos dicho, el relato parece mostrar al final la misericordia de Yahvé, pero el autor está diciendo algo más: no

${ }^{34}$ Cf. Jesús SAlazAR, «Caín errabundo, una historia borgiana», en: Il ritorno a casa. Actas del simposio internacional Poetica \& Cristianessimo, Roma: Edizione Universitá della Santa Croce 2005, pp. 413-420. 
hubo misericordia destinándolo al país de Nod. Pero, ¿quién fue el inmisericorde, Yahvé o el poeta del Génesis?

Si examinamos la manera en que están estructurados los relatos, con todo lo que dicen y lo que no dicen, podemos afirmar que el relato de Génesis reúne con mejores frutos las intenciones del poeta, pues no elimina ninguno de los elementos de importancia para la narración. Además, deja ver con mayor claridad el modelo racional que sostiene el relato. El autor del Génesis muestra una idea más clara de la racionalidad del orden humano dentro de un orden mayor; conoce mejor los motivos por los que su personaje debe sufrir un destino paradójico - en realidad, el relato nos dice que su destino es mejor de lo que nosotros sabemos al interpretar las intenciones del autor cuando lo aloja en Nod-.

En descargo del mito de Belerofonte se puede argumentar que se trata de un relato que no es central en la mitología griega, y que por lo tanto el desconocimiento de algunos detalles por parte de Homero se debe a la marginalidad del mito frente a otros mitos griegos. En ese sentido, el relato de Caín es el segundo gran mito fundacional de los orígenes del mundo hebreo luego del relato creacional - que incluye a Adán y Eva-; y además, es el primer gran relato en la cronología de los acontecimientos humanos una vez exiliados del jardín de Edén; se trata, por lo tanto, de un mito central de la tradición, y por ello el poeta se habría esmerado en no dejar inconexos ninguno de sus detalles.

Si pretendemos comprender la manera en que esos relatos fueron escritos y lo que quieren decir, entonces debemos dirigir la atención hacia algo más que problemas de transmisión y recepción de fuentes. Consideramos que el antiguo pecado contra el antiguo orden es el corazón de los relatos; en ambos casos hay una violación a la lógica antigua, al mundo con sus principios, a la sociedad con sus pilares, a la divinidad y el modo en que se espera que el hombre se dirija a ella. Los dos relatos ponen a sus personajes frente a las tres instancias más importantes, y los ponen en conflicto: Dios o los dioses, la tierra, el pueblo. El paradójico destino de Caín y Belerofonte es merecido, pues han sido ofensores de las tres instancias que gobiernan y dan sentido a la existencia. Ahora bien, este antiguo orden, ¿a qué se refiere? No se trata simplemente 
de las reglas fundacionales de cada cultura, de sus costumbres y ritos. El antiguo orden no se refiere solamente al ordenamiento original de las cosas, el modo en que se dispuso que estuvieran relacionadas; el antiguo orden señala o revela la causa, el motivo, el centro respecto del cual se relacionan y ordenan las cosas y los hombres. Por lo tanto, si el corazón de los relatos se encuentra en el antiguo pecado contra el antiguo orden, el corazón de este antiguo orden se encuentra en la ratio que es el centro de ese orden. Y eso, ese centro del antiguo orden, no se encuentra en ninguno de los casos en el escenario donde acontecen los relatos, en los avatares de Caín y Belerofonte, tan comunes y casi accidentales.

Ya hemos dicho que la centralidad o marginalidad de los mitos dentro de su tradición es un punto a considerar, sin embargo no es el único si se postula un mito anterior que haya sido el origen de los dos relatos (al momento, no nos ha sido posible identificar cuál habría sido dicho relato). Pero, además de su locus en la esfera de la tradición, y de haber postulado el antiguo orden como el corazón de los relatos, existe ese elemento central del orden; se encuentra presente en ambos relatos, y si hasta ahora no ha sido requerido es porque queda la impresión de que el paralelismo de los relatos no exige su estudio. Se trata de la presencia de Yahvé y Zeus. Pero es más que Yahvé y Zeus: nos remite, desde el punto de vista mitológico, al crimen religioso, encarnado en la ofensa a la diosa Gea o Madre Tierra. Los relatos no la mencionan, quienes aparecen son Yahvé y Zeus, que son la «versión» asimilada y autorizada de Gea en cada tradición: los hebreos al descubrírseles Yahvé dejan atrás los dioses y mitos paganos; los griegos, aunque conservan en sus mitos el linaje de Zeus como descendiente de Gea, refinaron su modelo divino en Zeus.

Así, los dos relatos muestran que los límites para comprender el destino paradójico de sus perseguidores están fundados en la compresión del centro que gobierna su racionalidad y da origen a sus costumbres, ritos, leyes y cosmovisiones: el orden divino. La siguiente tarea consistirá en explicar los caminos, distintos como hemos señalado, en que ese orden divino es asimilado en cada tradición, a la que nos han conducido Caín y Belerofonte.

El modelo de racionalidad que presentan los dos relatos es di- 
rectamente afectado por el papel de lo divino en cada relato. El modelo de racionalidad del relato de Caín difiere del modelo de racionalidad del relato de Belerofonte porque lo divino se define de diferente manera, su relación con lo humano tiene un tono distinto, y porque en la explicación de ese orden mayor el dios hebreo encarna una presencia muy distinta de la del dios griego. 


\section{RESUMEN}

El objetivo de este ensayo es poner a prueba los modelos de racionalidad presentes en dos relatos, uno en el libro del Génesis y otro en la Ilíada. Se trata del relato de Caín y el de Belerofonte. Nuestro trabajo en el análisis de los modelos de racionalidad de cada uno de los relatos, consistirá en confrontarlos, identificar sus orígenes y desarrollos comunes, y finalmente, proponer una lectura integradora donde los relatos sean aclarados el uno a la luz del otro. La pregunta de trabajo que acompañará en todo momento este estudio es: ¿qué entrevieron Homero y el Jahvista al hablar de Caín y Belerofonte como de un mismo hombre?, o bien ¿cuál es la racionalidad de cada modelo según nos cuentan en sus relatos?

Palabras clave: Caín, Belerofonte, Girard, fratricidio.

\section{ABSTRACT}

The aim of this paper is to explore two different types of rationality in two different tales, one in Genesis, the other in Iliad; the tales of Cain and Bellerophon. The author argues that is possible to illuminate both tales, throughout their models of rationality, in the light of each one, identifying their origins and their common developments. The two fundamental questions are: ¿Cain and Bellerophon are the same man? ¿Which are the models of rationality of both tales?

Key words: Cain, Bellerophon, Girard, fratricide. 